\title{
O ensino do judô paralímpico: a percepção dos técnicos brasileiros
}

\author{
Gabriela Simone Harnisch? \\ Jalusa Andreia Storch ${ }^{2}$ \\ Douglas Roberto Borella $a^{3}$ \\ Maria Luiza Tanure Alves ${ }^{4}$ \\ José Júlio Gavião de Almeida ${ }^{5}$
}

\section{RESUMO}

O objetivo do estudo foi verificar as práticas pedagógicas utilizadas por professores no ensino do judô para pessoas com deficiência visual. Para tanto, a pesquisa caracterizou-se como qualitativa descritiva, tendo como instrumento para coleta de dados um questionário aplicado à 14 professores e/ou técnicos participantes em uma das etapas do Campeonato Nacional do Judô Paralímpico. Em relação aos resultados, 11 professores afirmaram que tentam inicialmente trabalhar de forma verbal, e posteriormente, pautam-se no tato. Outros 3 professores utilizam-se somente do tato. Apenas 2 professores utilizam-se da tutoria. Assim, percebeu-se que a maior parte dos professores têm adequado suas práticas pedagógicas frente as características que seus alunos apresentam, porém, muitos avanços ainda são necessários.

Palavras-chave: Esporte para pessoas com deficiência. Artes marciais. Ensino. Docentes.

1 Doutoranda no Programa de Pós Graduação em Educação Física da Universidade Estadual de Campinas (FEF/ UNICAMP). Campinas/São Paulo, Brasil. E-mail: agaby_@hotmail.com

2 Doutora em Educação Física. Docente colaboradora do curso de Fisioterapia da Universidade Estadual do Oeste do Paraná (UNIOESTE). Cascavel/Paraná, Brasil. E-mail: jalusastorch@yahoo.com.br

3 Doutor em Educação. Docente efetivo do curso de Educação Física da Universidade Estadual do Oeste do Paraná (UNIOESTE). Cascavel/Paraná, Brasil. E-mail: douglasedufisica@yahoo.com.br

4 Doutora em Educação Física. Docente efetiva da Faculdade de Educação Física da Universidade Estadual de Campinas (FEF/UNICAMP). Campinas/São Paulo, Brasil. E-mail: malu@fef.unicamp.br

5 Doutor em Educação Física. Docente efetivo da Faculdade de Educação Física da Universidade Estadual de Campinas (FEF/UNICAMP). Campinas/São Paulo, Brasil. E-mail: gaviao@fef.unicamp.br

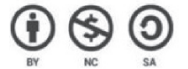

Este texto está publicado sob uma licenca Creative Commons Atribuição NãoComercial-Compartilhalgual - CC BY NC AS

Mais detalhes em: https://br.creativecommons.org/licencas/ 
Teaching the paralympic judo: a perception of the brazilian coachings

\begin{abstract}
The aim of this study was to verify the pedagogical practices used by teachers in judo teaching for visually impaired people. This study was characterized by the descriptive qualitative method, using a data collection instrument applied to 14 coaching and/ or technicians participating in one of the stages of the National Paralympic Judo Championship. The results showed that 11 coaching initially used verbal teaching techniques and later used touch techniques. In contrast, 3 coaching used only the touchtechniques. Only 2 coaching used tutoring techniques. This paper showed that most Brazilian coaching have adapted their pedagogical practices to the characteristics of their students with visual impairment, but many advances are still necessary.
\end{abstract}

Keywords: Sport for people with disabilities. Martial arts. Teaching. Faculty.

\title{
La enseñanza del judo paralímpico: una percepción de los técnicos brasileños
}

\section{RESUMEN}

El objetivo de este estudio fue comprobar las prácticas pedagógicas utilizadas por los profesores en la educación del Judo Paraolímpico en personas con discapacidad. Este estudio fue realizado con el método descriptivo cualitativo, utilizando el instrumentos de colecta de datos aplicado en 14 profesores y/o técnicos en una de las etapas del Campeonato Nacional de Judo Paraolímpico. Los resultados mostraron que 11 profesores utilizaron técnicas de enseñanza verbal. En contraste, 3 profesores utilizaron solamente técnicas táctiles. Otros 2 profesores utilizaron técnicas de tutoria. Este estudio muestra que los profesores/técnicos brasileños han adaptado sus prácticas pedagógicas a la configuración de sus estudiantes con discapacidad, pero muchos cambios y adaptaciones son todavia necesarios.

Palabras clave: Deporte para personas con discapacidad. Artes marciales. Enseñanza. Docentes. 


\section{INTRODUÇÃO ${ }^{6}$}

O esporte paralímpico envolve modalidades destinadas as pessoas com diferentes tipos de deficiência, podendo ser físico-motora, intelectual ou visual. Dentre as modalidades voltadas às pessoas com deficiência visual (DV) encontra-se o judô, que foi o primeiro esporte de origem asiática a ingressar no programa paralímpico, porém, desde a década de 1970 esta já era praticada por pessoas com DV. A estreia em paralimpíadas foi em 1988, em Seul, com a participação exclusiva de homens com deficiência visual, e mais tarde nas paralimpíadas de Atenas em 2004, as mulheres tiveram a sua primeira participação (CERQUEIRA, GOMES e ALMEIDA, 2012).

Em relação as regras da modalidade, as diferenças observadas entre o judô olímpico e paralímpico são mínimas, e têm como foco assegurar a segurança do atleta com DV durante as sessões de treinamento e competição esportiva, visto que a modalidade já se apresenta totalmente adequada às características da pessoa com deficiência visual, o que pode facilitar o trabalho dos professores frente ao ensino do judô paralímpico (OLIVEIRA FILHO e ALMEIDA, 2005; CERQUEIRA, GOMES e ALMEIDA, 2012; HARNISCH et al, 2014).

No processo de ensino e aprendizagem do judô paralímpico, é importante que os professores e técnicos estejam atentos as especificidades do aluno com DV. A atenção se deve, principalmente, quanto a algumas dificuldades que envolvem tal deficiência, como a recepção e interpretação das informações, aprendizagem de esquemas motores, aprendizagem por imitação, autoavaliação e controle das ações (SILVA, VITAL e MELLO, 2012; HARNISCH et al., 2014; HARNISCH et al., 2016).

Apesar das evidências apresentadas acerca da necessidade de estudos que auxiliem professores durante suas atividades docentes, os estudos realizados sobre o judô paralímpico ainda são poucos. Dentre estes, destacam-se as pesquisas realizados sobre a modalidade em suas diferentes formas de manifestação: iniciação (MIARKA et al., 2011; GUTIÉRREZ-SANTIAGO et al., 2013; HARNISCH et al., 2014; HARNISCH et al., 2016) e rendimento (GROSSO, 2006; GOMES, MORATO e ALMEIDA, 2011; GUTIÉRREZ-SANTIAGO et al., 2011; GONZÁLEZ, GUTIÉRREZ-SANTIAGO e AYÁN, 2012; SILVA et al., 2015). Percebe-se assim, que a maior parte dos estudos elucidados têm como foco a manifestação do judô paralímpico enquanto esporte de rendimento, com apenas dois trabalhos enfatizando o ensino da modalidade.

Voltado para a aprendizagem da modalidade, o estudo realizado por Harnisch et al. (2014) teve como objetivo verificar as práticas pedagógicas utilizadas por professores com os alunos com deficiência visual em aulas de judô, tendo como amostra 2 professores. A coleta de dados foi pautada na observação. Os resultados apontaram que as estratégias de ensino puderam ser otimizadas com o auxílio de colegas tutores (alunos sem deficiência participantes das aulas de judô) e o ensino individualizado nos momentos de maior dificuldade de assimilação do conteúdo pelo aluno com deficiência visual.

6 O presente estudo contou com o apoio financeiro do CNPq - Conselho Nacional de desenvolvimento cientifico e tecnológico. 
Em pesquisas realizadas com o objetivo de verificar as diferenças entre o judô olímpico e paralímpico, em relação ao tempo de combate evidenciou-se que as estruturas de tempo são diferentes, de modo que nas lutas de pessoas com DV as sequências de técnicas são mais curtas e necessitam de períodos de pausa mais longos devido ao comprometimento da visão. Neste ínterim, os estudos concluíram que adaptações devem ser realizadas ao treinamento de judô para pessoas com DV, afim de buscar melhores condições físicas durante as competições (GONZALEZ, GUTIÉRREZ-SANTIAGO e AYAN, 2012; GUTIÉRREZ-SANTIAGO et al., 2013)

Diante da presente contextualização, o judô paralímpico ainda se apresenta como um vasto campo de estudos devido a lacunas importantes ainda presentes, principalmente quando consideramos as estratégias de ensino utilizadas por professores e técnicos. Estudos nesta modalidade precisam ser realizados no sentido de investigar as adaptações necessárias para que o ensino e o treinamento se efetivem, sejam estes em relação aos materiais ou aos métodos de ensino utilizados pelos professores.

Neste contexto, o objetivo do estudo foi verificar as práticas pedagógicas utilizadas por professores no ensino do judô para pessoas com deficiência visual.

\section{MATERIAL E MÉTODOS ${ }^{7}$}

\section{Desenho do estudo}

O presente estudo ocorreu em uma das duas etapas nacionais do Grand Prix Infraero de Judô para Cegos realizado em São Paulo. A competição é aberta a praticantes de judô que tenham deficiência visual conforme a classificação esportiva da modalidade e sejam vinculados a Confederação Brasileira de Desporto de Deficientes Visuais (CBDV), com idade superior a 14 anos de idade. A escolha de realizar a coleta de dados neste ambiente se deu pela participação de um grande número de professores de judô paralímpico, oriundos de 11 estados brasileiros, em um único momento. Antes da competição, houve o contato com a CBDV que autorizou a realização da pesquisa.

Os professores participantes da pesquisa eram, em sua maioria, vinculados a academias de judô, nas quais pessoas sem deficiência praticam a modalidade, e neste mesmo espaço, contemplam alunos com DV. Apenas três (3) eram vinculados a Instituições de Ensino Especializadas (IEE) no atendimento a pessoas com DV.

Após o contato inicial com os professores, aqueles que aceitaram participar da pesquisa responderam um questionário visando verificar como ocorre o ensino do judô paralímpico.

7 Trata-se de uma pesquisa qualitativa descritiva, com aprovação pelo Comitê de Ética e Pesquisa, no dia 26/11/2013, sob CAAE24535513.0.0000.5404 


\section{Participantes}

Formaram a amostra do estudo, professores de atletas que participaram da I Etapa do Grand Prix Infraero de Judô para cegos, na qual comparece a maior parte dos atletas e técnicos brasileiros. Na referida competição foram contatados 19 professores, sendo que dentre estes, 14 aceitaram participar do estudo. Os professores eram oriundos de 11 estados brasileiros, de todas as regiões (sul, sudeste, centro oeste, norte e nordeste).

Assim, a amostra foi composta por 14 professores do gênero masculino. O tempo como professor de Judô teve média 19 anos. Vale ressaltar que três (3) professores (P1, P3 e P5) ministram suas aulas de judô em IEE. Abaixo, o quadro 1 apresenta a caracterização dos participantes:

Quadro 1 - Caracterização dos participantes ${ }^{8}$

\begin{tabular}{|c|c|c|}
\hline Participante & $\begin{array}{c}\text { Tempo como } \\
\text { professor }\end{array}$ & Formação \\
\hline P1 & 25 anos & Mestrado em Educação Física \\
\hline P2 & 17 anos & Graduação em Educação Física \\
\hline P3 & 4 anos & Graduação em Educação Física \\
\hline P4 & 12 anos & Graduação em Educação Física \\
\hline P5 & 4 anos & Graduação em Educação Física \\
\hline P6 & 25 anos & Graduação em Educação Física \\
\hline P7 & 15 anos & Pedagogia e Graduando em Educação Física \\
\hline P8 & 24 anos & Graduação em Educação Física \\
\hline P9 & 16 anos & Pós Graduação em Educação Física \\
\hline P10 & 34 anos & Graduação em Educação Física \\
\hline P11 & 18 anos & Graduação em Pedagogia e Direito \\
\hline P12 & 30 anos & Provisionado do CREF ${ }^{8}-$ Graduação em Ciências Contábeis \\
\hline P13 & 21 anos & Graduação em Educação Física \\
\hline P14 & 38 anos & Pós Graduação em Educação Física e Graduação em Ciências \\
\hline
\end{tabular}

Fonte: dados dos pesquisadores (2015)

\section{Coleta de dados}

Como instrumento para coleta de dados utilizou-se de um questionário elaborado e aplicado durante a competição já mencionada. Cada um dos participantes recebeu uma cópia do questionário e após responder os questionamentos solicitados, devolveu o mesmo

8 Refere-se a profissionais que comprovaram atividade profissional na Educação Física no período anterior à existência da Lei 9.696 de 01 de setembro de 1998, atendendo aos requisitos previstos nos incisos da Resolução 045/2002 (CONFEF, 2014). 
aos pesquisadores. O questionário foi composto, predominantemente, por questões abertas, abordando quatro itens:

- Identificação dos professores: enfatizou o tempo como professor de judô e a formação acadêmica;

- Técnicas e fundamentos: modelo seguido pelos professores durante o repasse dos conteúdos, seja pautado no tradicionalismo (a forma com que o judô foi criado no Japão, em 1882), ou se buscam atualizações referentes às técnicas e fundamentos;

- Cenário: remete-se aos materiais e espaços utilizados para as aulas, que tradicionalmente acontece só no tatame e sem os materiais comuns da Educação Física, como bolas, cordas, arcos.

- Ensino: refere-se aos métodos (auditivos e táteis) utilizados durante o ensino do judô para os alunos com DV. Ainda, questionou-se se existem outras estratégias para que o ensino do judô se efetive.

Para que os itens fossem contemplados, os questionamentos realizados foram:

a) Gênero / Idade / Cidade e Estado / Formação acadêmica / Tempo de experiência com a modalidade;

b) Em relação ao cenário (materiais, espaços), utilizados para a realização das suas aulas, quais você utiliza?

c) Em relação à modalidade (judô), você se utiliza de técnicas e fundamentos tradicionais ou busca novas técnicas?

d) Em relação aos personagens (alunos), como você realiza o ensino, ou seja, quais são os métodos e estratégias de ensino que você se utiliza?

e) Que outras observações você gostaria de apontar no que tange o processo de ensino à pessoas com deficiência visual?

\section{Análise dos dados}

Os dados coletados no presente estudo foram analisados perante análise de conteúdo sugerida por Bardin (2011). A mesma

Refere-se a um conjunto de técnica da análise das comunicações visando obter por procedimentos sistemáticos e objetivos de descrição do conteúdo das mensagens indicadoras (quantitativas ou não) que permitam a inferência de conhecimentos relativos às condições de produção/recepção (variáveis inferidas) destas mensagens (BARDIN, 2011, p. 44)

Sendo assim, as respostas foram organizadas em categorias. No item modalidade e cenário, foram quantificadas as respostas em relação ao ensino tradicional ou não, e as justificativas foram categorizadas conforme apareceram na coleta de dados. No item ensino, as respostas eram voltadas ao ensino de maneira auditiva ou tátil. Estas respostas foram quantificadas. Posteriormente, os professores enfatizaram as estratégias de ensino que se utilizam e foram categorizadas conforme o aparecimento, sendo a preocupação 
com o desenvolvimento dos alunos, a utilização do colega tutor, dentre outras categorias que surgiram conforme as respostas obtidas.

\section{Resultados e Discussão}

A apresentação e discussão dos resultados foi organizada de acordo com as abordagens direcionadas no instrumento de coleta de dados, ou seja, quanto aos professores, cenário, técnicas e fundamentos e por fim, o ensino.

\section{Professores}

Considerando a formação profissional da amostra elencada neste estudo, verificou-se que todos possuem formação superior em Educação Física (bacharel / licenciatura), sendo que um deles também possui a titulação de mestre em Educação Física. Além disso, um dos participantes é provisionado do Conselho Regional de Educação Física (CREF), conforme já elucidado anteriormente.

Com isso, percebeu-se que os professores envolvidos com o Judô Paralímpico buscaram entender a modalidade não apenas de forma isolada, mas como uma das possibilidades na Educação Física, o que facilita o ensino, a aprendizagem e o desenvolvimento dos seus alunos de forma global.

Por meio de uma pesquisa que visou verificar a formação de professores de judô, concluiu-se que

Exige-se conhecimento além da prática como atletas praticantes e uma formação mais especifica, como a graduação em Educação Física, para que ensinem judô com maior riqueza de conhecimentos científicos e bases didático-pedagógicas, que serão vivenciadas durante a sua vida acadêmica (GOMES et al., 2013, p. 43).

Uma das hipóteses estabelecidas para o fato dos professores de judô possuírem a graduação em Educação Física, segundo Drigo et al. (2011) é a regulamentação da profissão Educação Física (Lei 9.696/98) que desestabilizou, em um primeiro momento, a formação tradicional de faixa preta. Porém, as normas internacionais do judô, expressas pelas regras, motivaram adequações para a terminologia de professor para técnico, porém a formação deste técnico ainda é restrita ao termo, sem a devida adequação acadêmico-científica.

Assim, apesar da regulamentação do Professor de Educação Física, a atuação como técnico da modalidade em eventos de âmbito estadual e/ou regional requer apenas a graduação como faixa preta da modalidade, e muitas vezes, a realização do Curso de Credenciamento Técnico proporcionado pelas próprias federações (DRIGO et al., 2011).

Porém, quando as competições são organizadas pela Confederação Brasileira de Judô (CBJ), existe o artigo 19 que regulamenta a atuação do técnico: "Art. 19 - Para ter direito de participação nas Competições promovidas pela Confederação Brasileira de Judô, 
as Federações Filiadas deverão, além de atender às exigências Estatutárias da Entidade Dirigente do Judô Nacional, satisfazer as seguintes condições:(...) VII - Os técnicos das equipes deverão apresentar obrigatoriamente a Carteira de Registro no Conselho Regional de Educação Física - CREF" (Confederação Brasileira de Judô - CBJ, 2013, pp. 3-4).

Como a modalidade paralímpica segue a regulamentação estabelecida pela Federação Internacional de Judô - FIJ, consequentemente, a CBJ segue as mesmas tendências e normas em relação à formação do técnico.

Ao pensar na formação dos professores, quando a pessoa com DV busca um local para a sua atividade encontra normalmente um professor que ministra uma modalidade esportiva específica, mas que, entendendo somente das características específicas desta modalidade e não das especificidades reservadas a grupos de pessoas com deficiência, não consegue fazer as adaptações para a utilização de métodos de ensino adequados, assim, não enfatizando novas possibilidades de aprendizado para o seu aluno. Por outro lado, dentro das instituições de atendimento, comumente encontram-se professores que têm conhecimento acerca da deficiência, mas não conhecem o bastante a respeito das modalidades esportivas, não podendo assim proporcionar o aprimoramento técnico e tático do aluno dentro de alguma especialidade (OLIVEIRA FILHO e ALMEIDA, 2005).

Nesta pesquisa foi possível notar que, contrário aos autores supra citados, os professores que trabalham nas instituições de ensino especializadas possuem tempo de envolvimento com a modalidade, tendo média de 11 anos como professor de Judô.

\section{Cenário}

Em relação ao cenário utilizado para o ensino do judô, cinco professores utilizam o cenário tradicional da modalidade - o tatame. Os demais (nove professores), relataram que se ocupam também de cenários não tradicionais - exemplificados por cordas, bolas, arcos, cintos de tração, piscina, academia de musculação, pista de corrida e quadra de areia.

Em relação ao cenário, destaca-se o discurso do professor P1:

O cenário tradicional é de boa qualidade com sala ampla, livre de paredes e quinas (realidade conquistadaao longo do trabalho), recebemos kimonos dos projetos que nos auxiliam, o dojo (sala de judô) é composto por tatames mais baixos nas laterais (jogai), afim de que eles percebam o final da área.

O cenário tradicional do judô é o tatame, que por seu aspecto macio pode facilitar o deslocamento seguro das pessoas com DV. Quanto ao mesmo, nas IEE pode ser visto de maneira satisfatória, pois devido ao atendimento especializado, os materiais utilizados tendem a ser mais adequados às pessoas com DV.

Por meio dos relatos de todos os professores, percebeu-se que esta é a realidade de somente um dos professores participantes da pesquisa, devido as aulas acontecerem em um IEE, na qual os espaços são pensados para as pessoas com DV. Ou seja, dentre os 
participantes do estudo, somente um relatou que o tatame em que ministra aulas de judô não possui vigas e/ou paredes próximas.

Para os alunos com baixa visão, é significativa a utilização de contrastes nas cores no tatame, com cores fortes e que contrastem entre si, a ausência de paredes, quinas e vigas próximas ou no próprio tatame, para facilitar o deslocamento dos alunos com DV (ALMEIDA et al., 2010).

Segundo Almeida et al. (2010), o cenário é um item importante para garantir a segurança dos alunos durante os deslocamentos iniciais e incentivar as possibilidades de deslocamento de diferentes maneiras, em vários ritmos e direções. Além disso, salienta-se a relevância da utilização de materiais que favoreçam a percepção por parte das pessoas com DV, como bolas com guizos e outros dispositivos sonoros. Ainda, para as pessoas com baixa visão sugerem-se ampliações e padrões de brilho e contraste.

Recomenda-se também que, antes de aprender a movimentar-se por si mesmo, é importante conhecer o espaço em que está, neste caso, o local de prática do judô, com conceitos de posição, localização, direção e distância, no intuito de sanar dificuldades apresentadas pelas pessoas com DV quanto a orientação no espaço, importantes para a melhora na orientação e mobilidade independente (BUENO, 2003; HARNISCH et al., 2016)

Para facilitar o desenvolvimento das aulas, sugere-se as demarcações táteis no solo (por exemplo, colocar um fio que demarque todo o tatame e seja envolto por fita), introduzir referências sonoras e auditivas no ambiente (conduzida pelos professores, alunos ou alunos tutores), manter os equipamentos e materiais sempre organizados no espaço físico, alterar a luminosidade, dentre outros.

\section{Técnicas e Fundamentos}

Quanto as técnicas e fundamentos da modalidade, oito professores disseram que pautam-se nos procedimentos tradicionais, bem como dos não tradicionais, buscando sempre atualizações e novas variações e maneiras de melhorar o desempenho de seus alunos no Judô. Quanto a isso, destaca-se a ideia do professor P9:

Vou trabalhando a biomecânica do movimento otimizando e adaptando os movimentos dos golpes tradicionais, suprimindo etapas ou acrescentando outras.

Os outros seis professores declararam que empregam apenas o método tradicional, justificando principalmente a manutenção das características do esporte, conforme explicam os professores P3 e P6, respectivamente:

Ensino o Judô tradicional do Jigoro Kano.

Fundamentos tradicionais do judô - Go-kyo e Katame-waza.

Ao pensar nos aspectos referentes ao Judô, sendo ensinado de forma tradicional (da forma com que a modalidade foi criada e apresentada em 1882 por seu idealizador Jigoro 
Kano, ou da forma não tradicional (buscando novas combinações, técnicas e variações pautadas no que foi apresentado na sua criação), Gomes et al., 2013, p. 37, explica que "os professores de judô quase sempre utilizam o método tradicional, largamente baseado no censo comum, e pouca inovação tem acontecido com base em conhecimentos científicos" (GOMES et al., 2013, p. 37).

Estudos constatam que na formação dos professores de judô, o que se identifica são concepções de ensino ainda baseadas nos princípios filosóficos teóricos (lealdade, disciplina, humildade, justiça) idealizados por Jigoro Kano, criador do judô. Entretanto, Jigoro Kano teve também a preocupação em mostrar que o judô era uma combinação de luta dentro de um contexto cultural, assim, é considerado um meio interessante de cultura física. (GAMA e SILVA, 1999).

Por isso,

Deve-se entender que Jigoro Kano procurou soluções para os problemas existentes em seu país no século passado. O Brasil é um país de cultura diferente e os tempos também são outros, no que diz respeito às ideias e pensamentos. Ao iniciar a prática do judô e falar sobre seus ensinamentos, essas diferenças devem ser sempre levadas em consideração. Como em outras atividades esportivas que têm seus personagens sem adorá-los, o judô deve reconhecer o valor histórico do Jigoro Kano sem mistificá-lo ou dar-lhe cunho de religiosidade. (MESQUITA, 1994, p. 72).

Ruffoni (2004), explica que foi detectada uma incidência da diretividade no ensino da modalidade, sendo que por mais que os profissionais de Educação Física tenham conhecimentos afins e se esforcem para buscar uma metodologia contemporânea mais adequada ao judô, torna-se evidente que os seus hábitos e metodologias são provenientes da tradição milenar desta prática (RUFFONI, 2004).

Ou seja, ainda há a predominância do método de ensino artesanal, ou seja, mesmo os professores graduados em Educação Física utilizam estratégias parecidas com o que Ihes foi ensinado. Porém, para se trabalhar com o judô é necessário o conhecimento além da prática como atletas-praticantes e uma formação mais específica, como a graduação em Educação Física, para que ensinem o judô com maior riqueza de conhecimentos científicos e bases didático-pedagógicas, que serão vivenciadas durante sua vida acadêmica (GOMES et al., 2013).

Frente ao modelo artesanal, evidenciado nas pesquisas apresentadas por Olivio Junior e Drigo (2015) e Gomes et. al. (2013), os autores reconhecem que transformações sociais ocorreram e estas exigem mudanças no espaço do judô, de modo que o que mudou não foi o judô, mas sim a sociedade em que o mesmo está inserido.

Porém, não se pode deixar de lado a importância de manter os princípios da modalidade, de modo que estes regem e direcionam as práticas filosóficas e corporais do Judô. Rufino e Darido (2012, p. 296) reforçam essa ideia, explicando que "não se deve incriminar e julgar determinadas práticas relacionadas a estas manifestações centradas em outro prisma histórico. Pode-se, por outro lado, ressignificá-las, transformá-las e até mesmo mantê-las, porém considerando suas intencionalidades e particularidades". 
Com essa preocupação, o regulamento para exame e outorga de faixas e graus, divulgado pela CBJ em 2011, descreveu que

\begin{abstract}
Em 2006 iniciou-se no Japão o movimento de conscientização da necessidade de se voltar às origens do Judô, com objetivo de resgatar os valores históricos e culturais como também dos processos pedagógicos de ensino do Judô inseridos no contexto da formação do cidadão íntegro através da sua prática. A FIJ, órgão máximo na gestão do judô mundial, consciente da sua responsabilidade, tem tomado medidas para o resgate da essência do judô e, a mais importante, foi a alteração na regra de competição implantada em 2010 onde a verdadeira técnica característica do judô foi priorizada, em detrimento daquela que vinha sendo adotada em total desacordo com as raízes do nosso esporte (CBJ, 2011, p.2).
\end{abstract}

A transmissão dos grandes eventos judoísticos apresenta somente a parte concreta da modalidade, que é a luta pela conquista de medalhas tendo por consequência a projeção pessoal e institucional, deixando de mostrar a parte subjetiva, que é o aspecto filosófico, essência do Judô, que tem por objetivo a formação do cidadão. Esse fato está levando o ensino e à prática do Judô à tendências essencialmente competitivas, o que contraria frontalmente a proposta do criador de Judô, Mestre Jigoro Kano (CBJ, 2011, p.2).

O acontecido com o judô, ou seja, ter se tornado um esporte puramente de rendimento é chamado de esportivização. Breda et al. (2010, p.33) apontam que "o processo de esportivização das lutas trouxe novas formas de prática, locais de inserção, métodos de ensino e difusão, o que vem sendo novamente alterado com o processo de espetacularização dos eventos de lutas".

Assim, reporta-se aos discursos apresentados, de modo que é importante a manutenção dos princípios que direcionam o Judô desde a sua criação; porém, deve-se lembrar que as práticas devem ser estruturadas pautando-se também na cultura, nos costumes e nas condições de trabalho existentes.

\title{
Ensino
}

Em relação ao ensino, 11 professores afirmaram que inicialmente tentam ensinar de forma verbal, sendo que posteriormente usam o tato para sanar as dúvidas que ainda permaneceram. Ainda, três professores utilizam-se somente do tato para o ensino.

Dentre os participantes, dois professores enfatizaram que o ensino para pessoas com DV e pessoas videntes acontece da mesma maneira, não havendo diferenças frente aos métodos e estratégias de ensino a serem utilizados, conforme explicitado pelo professor P12:

Alguns técnicos tratam o aluno com deficiência de forma diferenciada, mas ele deveria ser tratado como os demais para se sentir incluído na modalidade. Para explicar, sempre falo, e se não houver entendimento eu demonstro por meio do tato, da mesma maneira que faço com os meus alunos que enxergam (P12). 
Quanto às estratégias de ensino, três professores relataram que pautam-se na utilização de colegas tutores, de modo a facilitar o aprendizado por parte do aluno com DV por meio da ajuda dos próprios colegas de turma, como o professor P7 salienta:

Em muitos casos, os professores ainda treinam seus atletas paraolímpicos separados dos regulares, isso dificulta o aprendizado, portanto todos devem treinar juntos. Para explicar, sempre peço auxílio para os demais colegas que estão na aula, e utilizo o tato (P7).

Dos 14 professores, sete apresentaram em suas justificativas preocupações referentes à conhecer os seus alunos, o nível de desenvolvimento que se encontram, bem como as suas percepções sobre as melhores maneiras de aprender, conforme explica o professor P9:

O processo de ensino para deficientes visuais, sem dúvida, é mais lento por si só, não se esquecendo que cada indivíduo responde de um jeito. Porém, o ensino deve ser fragmentado e respeitando as individualidades (P9)

Evidencia-se assim as divergências existentes entre os professores brasileiros de judô paralímpico quanto ao ensino, de modo que os dados revelados possibilitam uma gama de possibilidades para professores e técnicos, podendo fomentar treinamentos e programas de ensino da modalidade.

Mas, as pessoas com DV tem necessidade de adaptações e conhecimento pedagógico especifico. Para tanto, existe a necessidade de utilização de linguagem acessível, ajudá-lo na construção do referencial espacial, entender os elementos limitadores da aprendizagem e usar uma proposta pedagógica adequada.

Por isso, para melhor compreender os dados coletados referentes aos participantes, e consequentemente, aos métodos de ensino relatados pelos professores, reporta-se aos mecanismos de informação.

Sobre isso, Cobo, Rodriguez e Bueno (2003) defendem a importância da utilização dos estímulos auditivos como a primeira forma de aprendizagem, podendo assim favorecer o desenvolvimento de novas e eficientes habilidades. Oliveira Filho e Almeida (2005), corroboram que o processo de aprendizado deve ser direcionado por meios ricos em estímulos, que propiciem o desenvolvimento dos estágios e níveis de aprendizagem, diminuindo a lacuna no desenvolvimento motor causada pela baixa estimulação da visão.

Neste mesmo sentido, é relevante conhecer as características dos alunos, de modo que sabendo-se das vivências prévias será possível adequar e pautar-se em método de ensino adequados a cada pessoa (COBO, RODRIGUEZ e BUENO, 2003; HARNISCH et al., 2003)

Neste momento de conhecer o aluno com DV, Almeida et al. (2010) recomendam que seja identificada a causa da deficiência visual, o tempo decorrido desde a perda visual, o estado geral de saúde, e por último e não menos importante, o repertório motor, de modo que por meio das oportunidades de vivências motoras anteriores a pessoa com DV apresentará diferentes patamares de habilidades físicas. 
Quanto aos mecanismos de informação, averiguados por meio da pesquisa, Almeida et al. (2010), ressaltam que a utilização dos mesmos para com as pessoas com DV devem ser adequados aos níveis de complexidade que a tarefa exige.

Ao reportar-se aos professores que relataram que as práticas de judô acontecem de forma inclusiva, Oliveira Filho e Almeida (2005) destacam que incluir o indivíduo com DV implica inseri-lo em um ambiente que esteja preparado para aceita-lo, pronto para as mudanças e que possibilite essas alterações para facilitar a participação da pessoa com DV.

Para que intervenções de forma inclusiva possam ser efetivadas, é importante considerar que alguns movimentos se desenvolvem com maior tempo, ou seja, de modo atrasado quando comparado com pessoas que enxergam (COBO, RODRIGUEZ e BUENO, 2003; HARNISCH et al., 2016). Assim, ressaltando que as posturas e movimentações são características do Judô, o ensino das mesmas deve ser pautado com maior atenção, para que não prejudique a aprendizagem dos demais fundamentos da modalidade.

A maior parte das dificuldades encontradas nas aulas podem ser substituídas por um auxiliar - no caso, o tutor. Porém, sabe-se que muitas vezes a contratação de mais um professor não é possível, então, é interessante recorrer a tutoria durante as aulas, ou seja, preparar outra pessoa praticante da modalidade para ajudar o colega com deficiência, fornecendo para a pessoa com DV um maior número de informações e feedback (NABEIRO, 2002; PEDRINELLI e NABEIRO, 2012). A pesquisa desenvolvida por Harnisch et al (2014), confirmou a importância da utilização do colega tutor para o ensino do judô no contexto inclusivo, sendo que o mesmo prestou auxílio durante as aulas.

Sobre isso, Oliveira Filho e Almeida (2005, p. 94), explicam que a intervenção junto às pessoas com deficiência que busque o princípio de concepções igualitárias e ideais do ser humano leva à uma adaptação "tentando adequar o inadequado", já que cada pessoa é diferente e única. Assim, trata-las com método de ensino esportivo destinado às pessoas sem deficiência é buscar uma pseudo igualdade, utilizando princípios que são construídos a partir da lógica da exclusão.

As variáveis que cercam o processo de ensino mostram a necessidade de intervenção especificas por pessoas capacitadas. É preciso profissionais que entendam não somente das características do esporte, mas também de como adaptar e dar condições para o aprendizado do sujeito com limitações visuais (OLIVEIRA FILHO e ALMEIDA, 2005).

Dentro de um grupo, a diferença tem de ser respeitada. Não temos em um grupo duas pessoas iguais, nem com as mesmas limitações e potencialidades. O bom educador terá de interagir da melhor maneira dentro das diferenças, entendendo que o princípio da desigualdade implica tratar cada pessoa de uma maneira diferente. Tratar duas pessoas de maneira igual é desrespeitar as suas características. Não podemos ensiná-las e nem premiá-las da mesma forma (OLIVEIRA FILHO e ALMEIDA, 2005, p. 100).

Por fim, é importante propiciar um ambiente adequado para que o aluno encontre o esporte e nele possa desenvolver todas as suas potencialidades, utilizando-a como um 
meio para o aprendizado, independentemente de este se apresentar voltado para o alto rendimento, para o lazer, para a reabilitação ou para a educação (OLIVEIRA FILHO e ALMEIDA, 2005, p. 107)

\section{CONSIDERAÇÕES FINAIS}

Reportando-se aos objetivos propostos para o referido estudo, percebeu-se que os professores participantes estão adequados quanto a qualificação exigida, ou seja, possuir e graduação em Educação Física.

Em relação à modalidade, percebeu-se que os professores buscam, pesquisam e tentam estar sempre atualizados que as regras e fundamentos a serem utilizados. Porém, uma pequena parcela dos professores, apesar de estarem no século XXI, ou seja, muito tempo após a criação e sistematização da modalidade, ainda temem a utilização de novas técnicas, fundamentos e recursos para a aprendizagem do Judô, mesmo com a manutenção dos princípios que regem o esporte.

Apesar disso, alguns relatos demonstram de forma satisfatória o quanto os professores buscam qualificação e preparo para ministrar suas aulas de judô, deixando evidente que tentam adequar-se às condições e peculiaridades de cada aluno em relação à captação de informações.

Notou-se também, que alguns poucos professores utilizam de métodos de ensino que facilitam o trabalho docente, mas esquecem da importância da estimulação verbal e das demais formas de percepção das informações que seus alunos podem se pautar, o que se utilizado poderá auxiliar no processo de desenvolvimento motor, cognitivo, intelectual e social das pessoas com deficiência visual.

Acerca do ensino, foi possível evidenciar que os participantes se utilizam da verbalização e do tato para o ensino. Todavia, alguns relataram ensinar somente pelo tato, o que pode acarretar em limitações na formação global do praticante de judô que apresenta, dentre as suas características, a deficiência visual.

Por fim, espera-se que este estudo possa contribuir de forma a auxiliar professores de judô que visem o ensino à pessoas com deficiência visual, além de estimular a realização de mais pesquisas com a mesma temática.

\section{REFERÊNCIAS}

ALMEIDA, José Júlio Gavião et al. Educação Física e Esportes Adaptados à Pessoas com Deficiência Visual. In: SAMPAIO, Marcos Wilson et al (orgs.). Baixa Visão e Cegueira: os caminhos para a reabilitação, a educação e a inclusão. Rio de Janeiro: Cultura Médica, 2010. Cap. 35. p. 497-509.

BARDIN, Laurence. Análise de Conteúdo. Lisboa: Edições 70, 2011. 280 p

BRANCATTI, Paulo Roberto. Atividade Motora Adaptada para pessoas deficientes visuais. In: MARQUEZINE, Maria Cristina; ALMEIDA, Maria Amélia; TANAKA, Eliza Dieko 
Oshiro (orgs.). Perspectivas Multidisciplinares em Educação Especial II. Londrina: Eduel, 2001. Cap. 23. p. 293-299.

MARTíN, Manuel Bueno. Motricidade e Deficiência Visual. In: MARTíN, Manuel Bueno; BUENO, Salvador Toro (org.). Deficiência Visual: Aspectos Psicoevolutivos e Educativos. São Paulo: Santos, 2003. Cap. 9. p. 145-154.

CERQUEIRA, Diego; GOMES, Mariana Simões Pimentel; ALMEIDA, José Júlio Gavião de. Judô. In: MELLO, Marco Túlio de; WINCKLER, Ciro (org.). Esporte Paralímpico. São Paulo: Atheneu, 2012. Cap. 18. p. 161-168.

COBO, Ana Delgado; RODRÍGUEZ, Manuel Gutiérrez; BUENO, Salvador Toro. Desenvolvimento cognitivo e deficiência visual. In: MARTíN, Manuel Bueno; BUENO, Salvador Toro (org.). Deficiência visual: aspectos psicoevolutivos e educativos. São Paulo: Santos, 2003. Cap. 6. p. 128-144.

COMITÊ OLÍMPICO BRASILEIRO - COB. Esportes: Judô. 2015. Disponível em: < http:// www.cob.org.br/esportes/esporte.asp?id=18>. Acesso em: 26 mar. 2015.

CONFEDERAÇÃO BRASILEIRA DE JUDÔ - CBJ. Regulamento para exame e outorga de faixas e graus. 2011. Disponível em: < https://docs.google.com/file/d/0B1JDeQMYqKmr Y2Q2Njg4YWEtMTgzOC00MDFiLWFmYWUtMDhjNGIOMjJmNzZk/edit?hl=pt_BR >. Acesso em: 20 jul. 2014.

CONFEDERAÇÃO BRASILEIRA DE JUDÔ - CBJ. Normas Gerais para Eventos Nacionais 2013. Disponível em: < http://www.cbj.com.br/painel/arquivos/documentos oficiais/113458250213normas-gerais_eventos-nacionais_2013(1).pdf >. Acesso em: 20 jul. 2014.

CONSELHO FEDERAL DE EDUCAÇÃO FÍSICA - CONFEF. Resoluções. Disponível em: < http://www.confef.org.br/confef/resolucoes/>. Acesso em: 08 jun. 2014.

DRIGO, Alexandre Janotta et al. Artes marciais, formação profissional e escolas de ofício: Análise documental do judô brasileiro. Motricidade, Ribeira de Pena - Portugal, v. 7, n. 4, p.49-62, 1 out. 2011. Trimestral.

SILVA, Marco Aurélio da Gama e. As Perspectivas do Imaginário Social das Crianças e Jovens Praticantes de Judô na cidade do Rio de Janeiro. 1999. 107 f. Dissertação (Mestrado) - Curso de Educação Física, Universidade do Estado do Rio de Janeiro, Rio de Janeiro, 1999.

GOMES, Fábio Rodrigo Ferreira et al. Influência da formação em Educação Física em professores de Judô. Science In Health, São Paulo, v. 4, n. 1, p.36-44, jan. 2013. Trimestral.

GOMES, Mariana Simões Pimentel; MORATO, Marcio Pereira; ALMEIDA, José Júlio Gavião. Judô paraolímpico: comparações e reflexões sobre as realidades de diferentes seleções femininas. Conexões, Campinas, v. 9, n. 2, p.85-109, jul. 2011. Trimestral.

GUTIERREZ-SANTIAGO, Alfonso et al. Are Male Judokas with Visual Impairments Training Properly? Findings from an Observational Study. Journal of Visual Impairment \& Blindness, Huntington, v. 106, n. 4, p.224-234, abr. 2012.

GROSSO, Francisco et al. Perfil somatotípico e composição corporal de atletas de judô brasileiros masculinos cegos e deficientes visuais. Revista Digital, Buenos Aires, v. 11, n. 106, p.1-10, mar. 2017. 
GUTIÉRREZ-SANTIAGO, Alfonso et al. T-Pattern Detection in Judo Combat: An Approach to Training Male Judokas with Visual Impairments According to their Weight category. International Journal of Sports Science \& Coaching, Montpellier, v. 8, n. 2, p.385394, jan. 2013.

HARNISCH, Gabriela Simone et al. Práticas pedagógicas utilizados por professores de judô no ensino de crianças com deficiência visual. Conscientiae Saúde, São Paulo, v. 13, n. 1, p.52-55, jan. 2014. Trimestral.

INSTITUTO BRASILEIRO DE GEOGRAFIA E ESTATÍSTICA - IBGE. Características gerais da população, religião e pessoas com deficiência. 2010. Disponível em: < http://loja. ibge.gov.br/censo-demografico-2010-caracteristicas-da-populac-o-e-dos-domiciliosresultados-do-universo.html>. Acesso em: 15 mar. 2013.

MESQUITA, Chuno Wanderlei. Identificação de incidências autoritárias existentes na prática do judô e utilizadas pelo professor. 1994. 110 f. Dissertação (Mestrado) Curso de Educação Física, Centro de Ciências da Saúde, Universidade Federal do Rio de Janeiro, Rio de Janeiro, 1994.

MUNSTER, Mey de Abreu van; ALMEIDA, José Júlio Gavião de. Um olhar sobre a inclusão de pessoas com deficiência em programas de atividade motora: do espelho ao caledoscópio. In: RODRIGUES, David (org.). Atividade Motora Adaptada: a alegria do corpo. São Paulo: Artes Médicas, 2006. Cap. 4. p. 81-91.

OLIVEIRA FILHO, Ciro Winckler de; ALMEIDA, José Júlio Gavião de. Pedagogia do Esporte: um enfoque para pessoas com deficiência visual. In: PAES, Roberto Rodrigues; BALBINO, Hermes Ferreira (org.). Pedagogia do Esporte: Contextos e Perspectivas. Rio de Janeiro: Guanabara Koogan, 2005. Cap. 6. p. 91-110.

PEDRINELLI, Verena Junghahnel; NABEIRO, Marli. A prática do esporte pela pessoa com deficiência na perspectiva da inclusão. In: MELLO, Marco Túlio de; WINCKLER, Ciro (orgs.). Esporte Paralímpico. São Paulo: Atheneu, 2012. Cap. 3. p. 21-25.

RUFFONI, Ricardo. Análise metodológica na prática do Judô. 2004. 109 f. Dissertação (Mestrado em Motricidade Humana), Universidade Castelo Branco, Rio de Janeiro, 2004. RUSSO JÚNIOR, Walter; SANTOS, Leonardo José Mataruna dos. O Judô como atividade pedagógica desportiva complementar, em um processo de orientação e mobilidade para portadores de deficiência visual. Revista Digital, Buenos Aires, v. 7, n. 35, p.110, abr. 2001.

SILVA, Andressa; VITAL, Roberto; MELLO, Marco Túlio de. Deficiência, incapacidades e limitações que influenciam na prática do esporte paralímpico. In: MELLO, Marco Túlio de; WINCKLER, Ciro (Org.). Esporte Paralímpico. São Paulo: Atheneu, 2012. Cap. 7. p. 20-31.

THOMAS, Jerry; NELSON, Jack K.; SILVERMAN, Stephen J. Métodos de pesquisa em atividade física. 6. ed. Porto Alegre: Artmed, 2012. 478 p.

Recebido em: Julho/2017

Aprovado em: Fevereiro/2018 